\title{
A GAMIFICATION TECHNIQUE TO INCREASE ENGAGEMENT IN ASYNCHRONOUS ONLINE DISCUSSIONS
}

\author{
Brian S. Bovee, Dakota State University, brian.bovee@trojans.dsu.edu \\ Thomas Jernejcic, Dakota State University, thomas.jernejcic@trojans.dsu.edu \\ Omar El-Gayar, Dakota State University, omar.el-gayar@dsu.edu
}

\begin{abstract}
Engaging students in online discussions is difficult. This paper presents a method for gamifying asynchronous online discussions in order to increase student engagement. The method was evaluated in two sections of an online, graduate business information systems course which were identical with the exception that one course added a game element to the discussion board. Two forms of engagement were evaluated using different methods. Overall, the result of the gamified discussion board was an improvement in both the behavioral and cognitive engagement of students participating with the discussion. Our findings yield important theoretical and practical implications on how to successfully implement and evaluate a gamified discussion board. Limitations and suggestions for future research are also discussed.
\end{abstract}

Keywords: Gamification, online discussion, design science, flow theory, leaderboard

\section{INTRODUCTION}

Online discussions are critical to online education as a means for student collaboration, enhancing learning and supporting intrinsic motivation to succeed. Engagement in online discussions, however, is difficult to maintain (Cheung \& Hew, 2005; Cheung \& Hew, 2005; Delaney et al. 2019; Hewitt, 2005; Silva et al. 2019; Xu et al. 2020;). Gamification, defined as the use of game design elements for non-game applications (Deterding et al. 2011), has been proposed as a method that can promote learning and engagement (Kapp, 2012). Thus, while the research supporting gamification and learning is prevalent, studies examining the gamification of online discussions are sparse (Ding et al. 2017; Ding et al. 2018; Ding et al. 2019; Hanus \& Fox, 2015). Accordingly, the goal of this study was to use design science (Hevner et al. 2004) to create a method for the gamification of an asynchronous online discussion board. The method was evaluated in two sections of an online, graduate business information systems course. The sections were identical with the exception that experimental course used a leaderboard in the online discussion. This paper contributes to the extant literature by creating a method for the gamification of online discussions guided by flow theory (Csikszentmihalyi, 1998) and evaluating the effectiveness of the gamified discussion board based on the student's behavioral and cognitive engagement.

Consistent with Fredericks et al. (2004) established model for engagement, the goals of gamifying an asynchronous online discussion board were to develop active participation in discussions and facilitate higher level cognitive thinking. To that end, the following research questions were proposed:

RQ1: To what extent is the gamification of an asynchronous online discussion board positively related to active participation?

RQ2: To what extent is the gamification of an asynchronous online discussion board positively related to increased cognitive performance?

It is hypothesized that the course using the gamified discussion board will generate more total posts and replies than the non-gamified course. Variables to be compared to determine if gamification led to increased engagement with the discussion board included total posts, replies, likes, and views in both courses. It is predicted that the gamified course will lead to higher cognitive thinking in students than the non-gamified course as evidenced by the average grade for discussions in each course. 
From a theoretical perspective the research provides insights into the role of gamification of online discussions in inducing active engagement and increased cognitive performance. It also demonstrates a gamification design process to create a leaderboard game element that promotes constructive competition. From a practical perspective, the research provides a framework to address low student engagement in asynchronous online discussions reflected in both the quality and quantity of student posts.

The remaining sections of this paper are as follows. First, section "Related Work" presents related studies on gamification and asynchronous online discussions. This is followed by the section "Method" which describes the empirical investigation instruments used in evaluation of the prototype. Next, the section "Results" presents the results of evaluation followed by the section "Discussion" which interprets the results. Finally, the last two sections "Limitations and Future Research" and "Conclusion" identify specific limitations in the present study, opportunities for future research, and a conclusion concluding the paper.

\section{RELATED WORK}

\section{Gamification and Learning}

Gamification involves the use of game design elements for non-game applications (Deterding et al. 2011). While "serious" games are designed for a purpose other than pure entertainment, gamification involves the application of game-like elements such as leaderboards, digital badges, and point systems to increase engagement and tap the learner's normal drive for achievement (Deterding et al. 2011; Cronk, 2012). Findings in the current literature regarding the use of gamification to promote learning are mixed. The majority of the research demonstrates the ability of gamification to promote intrinsic motivation to learn (Leong \& Luo, 2011; Ding, Kim \& Orey 2017) and encourage participation (Barata, Gama, Jorge, Gonçalves, \& Fonseca, 2013). However, a few studies have found gamification to result in lower intrinsic motivation and satisfaction compared to the non-gamified groups (Hanus \& Fox, 2015).

Reasons for the mixed results are attributed to poor gamification design and to suboptimal research design (Caponetto et al., 2014; Dicheva et al., 2015). One example of poor gamification design in the literature is creating destructive competition. For example, game elements such as leaderboards or badges can result in either destructive or constructive competition (Fülöp, 2009). Destructive competition occurs when participants feel forced or controlled by the competition (Fülöp, 2009; Ryan \& Deci, 2000). Constructive competition occurs when participants enjoy the activity, identify with the activity, and integrate it into their own sense of self (Ryan \& Deci, 2000; Csikszentmihalyi, 1998). Leaderboards can promote constructive competition by displaying only top performers and, therefore, not alienate lower performers. Hanus and Fox (2015) acknowledge that a key reason gamification may have failed in their study was a result of destructive competition in the leaderboard and a gradual reduction in the novelty of using digital badges. In addition to poor gamification design, a second reason for the mixed results in the literature stems from the majority studies using descriptive statistics (Hamari et al., 2014) and not including a control group. While descriptive statistics provide valuable information, by themselves, they do not provide sufficient evidence to generalize beyond the study group (Ding, 2019).

\section{Asynchronous Online Discussions}

Asynchronous online discussions represent a critical aspect of the online learning process. Low student engagement, in the form of low quantity and quality of posts, has represented a significant challenge to overcome for instructors (Xu et al. 2020; Delaney et al. 2019; Silva et al. 2019; Hara, Bonk, \& Angeli, 2000; Hewitt, 2005). While engagement has been defined in many ways, Fredericks et. al (2004) widely accepted (da Rocha et al. 2016; Finn \& Zimmer, 2012; Kwan \& Hew, 2018) model of engagement focuses on examining the three elements of how students feel, behave, and think. Accordingly, in the present study, engagement in online discussions was evaluated based on behavioral (active participation) and cognitive engagement (Fredericks et al. 2004).

Active participation in online discussions involves behavioral aspects of composing original posts, reading or viewing other posts, and responding to other student posts. Game design elements such as leaderboards or digital badges provide external motivation to engage with discussions via constructive competition toward a goal (Ding, 2019). As the user engages with the game, the motivation to engage can shift from extrinsic to intrinsic (Lepper, 1988; Deci, Eghrari, Patrick, \& Leone, 1994). Self Determination Theory (Ryan \& Deci, 2008) and Flow Theory 


\section{Issues in Information Systems}

Volume 21, Issue 3, pp. 20-30, 2020

(Csikszentmihalyi, 1998) describe this as a process in which one identifies with an activity's value and integrates it into their sense of self.

In applying flow theory to gamification of asynchronous discussions, students are more likely to be motivated to engage with the discussion by clear goals (Locke \& Latham, 2006), challenging content, and appropriate feedback. When expectations are not set or vague, students struggle with both the amount and type of content in posts (Dennen, 2007).

In order for learning to occur, active participation must be accompanied by cognitive thinking in the discussion. Active participation, alone, will not result in the desired outcome of learning. Common strategies for developing cognitive thinking in discussions include instructor scaffolding (Zhu, 2006), clear guidelines (Ng, Cheung \& Hew, 2009), and critical thinking questions (Garrison, 2005). Game elements can provide the intrinsic motivation for students to critique, construct, and comprehend knowledge in the context of online discussions (Goa, Wang, \& Sun, 2009; Ding, 2019). For example, in a recent study using digital badges, more students in the gamified group reported the online discussions forced them to think harder than students in the non-gamified group (Ding, 2019).

In summary, based on the aforementioned review of the literature, the current study addresses several limitations in current studies. First, the study uses a research design including a control group. Second, the study uses design science to guide the gamification design process to create a leaderboard game element that promotes constructive competition. Third, the study provides a framework to address low student engagement in asynchronous online discussions reflected in both the quality and quantity of student posts.

\section{METHOD}

Using flow theory (Csikszentmihalyi,1998) as the theoretical foundation, a method for the gamification of an online, asynchronous video discussion board was developed for higher education following design science research guidelines (Hevner, 2004). The method contains three main components: a database to import discussion board data, a webpage displaying a leaderboard to gamify the discussion board, and a series of reports to assist both researchers and instructors using the tool (Figure 1).

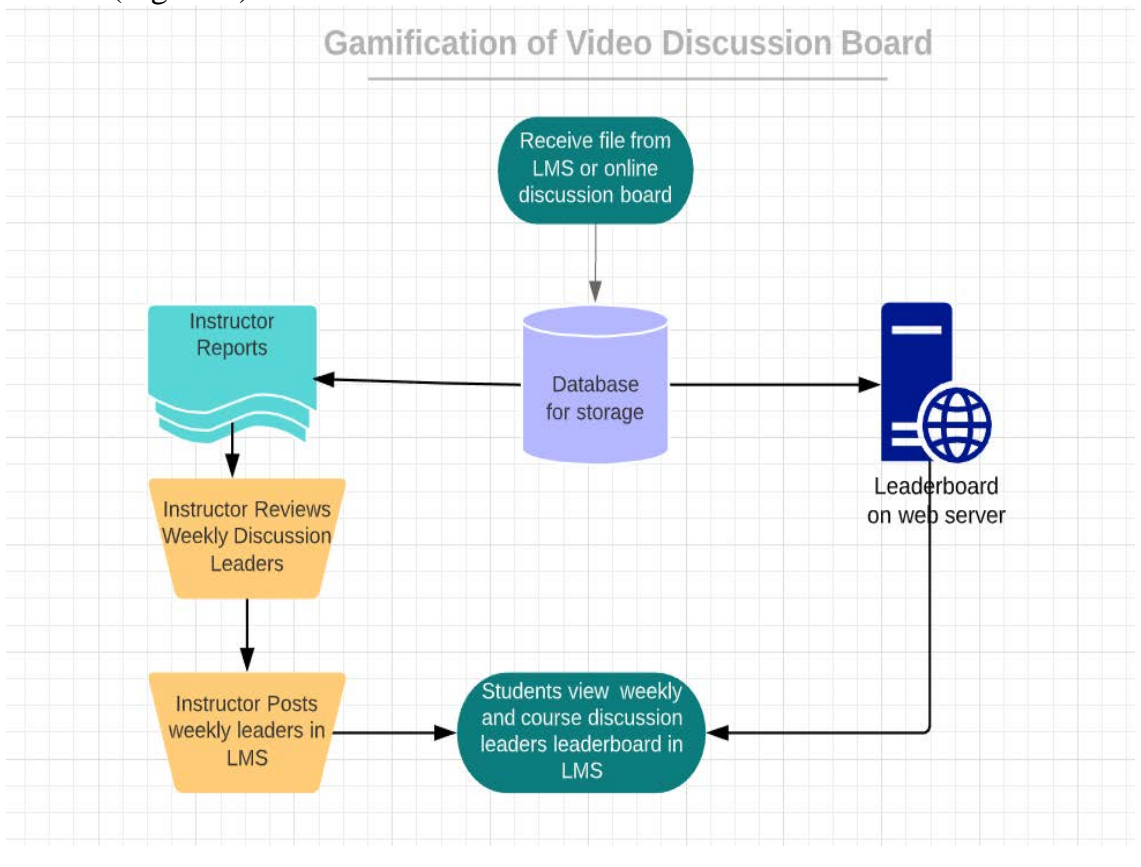

Figure 1. Gamification of Online Discussions 
First, each week a file is exported from the discussion forum for the course with all data pertaining to the previous week's discussion posts/replies for the course. Second, the file is imported into a database where the instructor can a) run weekly reports to acknowledge top-performing students from the prior week's discussions, and b) export the data to a leaderboard website that informs students of the top-performing students for the discussion posts/replies in the entire course.

The proposed method satisfies elements of flow theory (Csikszentmihalyi,1998; Nakamura and Csikszentmihalyi, 2014) to induce a state of flow resulting in improved engagement with the discussion as summarized in Table 1. First, in order to achieve a state of flow, the artifact must have clear goals to allow proper focus on the task at hand (Csikszentmihalyi,1998; Cowley et al. 2008). The goal in the present study was simple and clear: to "lead the discussion" by being in the top $20 \%$ of all posts and replies for the course. Students were informed of the goal at the beginning of the course and reminded of the goal in each subsequent week to ensure there was no ambiguity in the goal.

Second, in order to achieve flow, the artifact must provide clear feedback to ensure the individual will not end the state of flow by losing concentration (Cowley et al. 2008; Nakamura \& Csikszentmihalyi, 2014). In the present study, two decisions were made to provide students with the required clear and timely feedback. First, the instructor used a report to acknowledge the weekly discussion leaders each week. Second, a web-based leaderboard provided instant and timely feedback to the students seeking information on their performance in the game.

Finally, a third element of flow theory is inducing an appropriate level of challenge to ensure the student has confidence to complete the task but yet induces complete immersion in the task (Csikszentmihalyi,1998; Cowley et al. 2008; Nakamura \& Csikszentmihalyi, 2014). In order to achieve the appropriate level of challenge, the decision was made to use a video-based discussion board. Data from course surveys seemed to confirm video-based discussions have a unique ability, as opposed to traditional text discussion boards, to induce the appropriate level of challenge and improve social presence (Clark et al. 2015). In the next section, specific details of the game are discussed as well as the supporting elements of the artifact.

Table 1. Elements of Flow Theory and Associated Design Decisions(s)

\begin{tabular}{|l|l|}
\hline \multicolumn{1}{|c|}{ Elements of Flow } & \multicolumn{1}{c|}{ Design Decisions(s) } \\
\hline $\begin{array}{l}\text { Clear goals (Cowley et al. 2008; } \\
\text { Csikszentmihalyi,1998; Nakamura and }\end{array}$ & $\begin{array}{l}\text { Goal: Be a "discussion leader”; top 20\% of posts/replies for the } \\
\text { week and course. }\end{array}$ \\
\hline $\begin{array}{l}\text { Feedback is clear and timely } \\
\text { (Csikszentmihalyi,1998; Cowley et al. }\end{array}$ & $\begin{array}{l}\text { First, students were informed each week of discussion leaders for } \\
\text { the prior week. Second, students were able to, at any time, access } \\
\text { the online leaderboard to receive feedback on game performance. }\end{array}$ \\
\hline $\begin{array}{l}\text { Artifact must be simple to understand but } \\
\text { challenging enough to induce a state of } \\
\text { flow (Csikszentmihalyi,1998; Cowley et } \\
\text { al. 2008). }\end{array}$ & $\begin{array}{l}\text { Use of video discussion boards, as opposed to traditional text- } \\
\text { based discussions, provide an appropriate level of challenge to } \\
\text { induce flow. }\end{array}$ \\
\hline
\end{tabular}

\section{Prototype Demonstration}

The present study used a free online, video-based discussion board called Flipgrid for students to discuss concepts in a graduate business information systems course. Students recorded a 1-2 minute discussion post using their webcam or cell phone. In addition, students viewed other student posts in the forum as well as left video replies to other recorded posts. The object of the developed game was to "lead the discussion" in terms of total posts/replies in the course. Students in the top $20 \%$ of the class in terms of total posts/replies at the end of the course were considered the winners in the game. Weekly updates were used to identify students who were top performers for the week. In addition, a website was created as shown in figure 2 for students to track the current leaders for the entire course.

The first design artifact created was a database that can import data from any discussion board or learning management system which has the ability to export discussion data to a CSV or Excel file. The database included a single table entitled 'flipgrid'. Within the instructor area of the Flipgrid website there was an option to export discussion forum 
data to a CSV file. Data was then imported into the table using the export feature in the Flipgrid educator area. It is important to note that the database was designed to accept data from any other learning management system or discussion forum.

The second component of the artifact in this study is a website developed to display the students who are leading the course in total posts and replies as shown in Figure 2. The website data was derived from exporting a report of the discussion data in the database to an HTML template stored online. The header of the webpage was designed to be easily modified by instructors or future researchers via editing the page in MS Word or any HTML editor to reflect the unique nature of any game. The data is derived from a customizable report in the database. An important feature of the website is that the report that generates the website data prompts the instructor for a minimum number of posts. Answering 0 to the prompt would display total posts for all students in the course. However, an important aspect in the design of the gameboard was to promote constructive competition (Fülöp, 2009) by rewarding top performers while not alienating lower performing students. Therefore, the prompt for a minimum number of posts allows the instructor to run the report as needed to identify only the top performing students.

\section{CONGRATULATIONS! Here are the Current Top Students for BUS 512 FA 19 AE Total Posts \& Replies!}

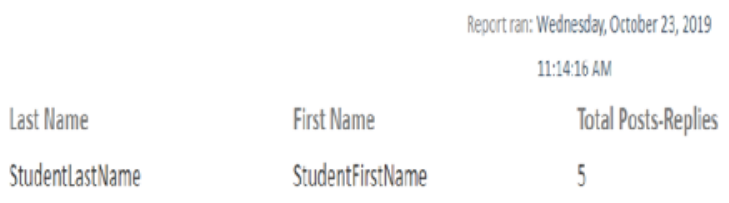

Figure 2. Website for leaderboard

Finally, a series of reports were developed to assist both researchers and instructors in analyzing the discussion data. It is envisioned these reports can assist with providing valuable data for new versions of gamification of discussion boards as well as assist instructors with motivating students to actively engage with the game. In the present study, for example, a report is used to track the top 3 leaders each week in discussion posts and replies. The leaders were then recognized each week in a weekly announcement and posted in the learning module.

\section{Evaluation}

Two sections of an online business information systems course formed the basis for the evaluation of the prototype. The two courses were taught by the same instructor and shared similar characteristics in every way including the use of a discussion board to discuss concepts related to the course. One section had 27 students and the other section had 25 students.

Students were required to do a weekly video post and reply via video to two other student posts. The one exception between the sections was the use of the leaderboard in one of the two courses. In the course with the leaderboard, students received weekly updates on the top discussion leaders for the prior week. In addition, this gamified course allowed students to access the leaderboard website at any time to visualize the current leaders in the course in terms of posts and replies. Each week the instructor reviewed content in the posts and replies to ensure students did not attempt to cheat by creating less qualitative contributions in order to win the game. At the conclusion of the eight- 
week course, a detailed analysis was performed between the two courses to ascertain if the introduction of the gameboard had the expected result of increased engagement with the discussion.

\section{RESULTS}

RQ1: To what extent is the gamification of an asynchronous online discussion board positively related to active participation?

Analysis consisted of statistical discovery of mean differences between the control group (non-gamified course) and the treatment group (gamified course). The control group is identified as group 1 and the treatment group as group 2 . Variables observed and analyzed include total posts, replies, views, and likes. In addition, analysis was conducted on the total sum of activities for each group. Significance levels (alpha) of 0.05 and 0.10 were utilized for investigation of the data collected.

First, we calculated statistical measures of central tendency and dispersion for each variable for each group as shown in Table 2. The populations of each group are similar with 248 points of activity for the control group (1) and 236 for the treatment group (2). Regarding posts, we observe a mean of approximately 1.08 versus 1.05 with standard deviations of 0.3268 and 0.2559 respectively. Minimum, median, and maximum are the same. Consequently, we observe a slight decrease between groups when focusing on student posts. Regarding replies, we observe a mean of approximately 1.52 versus 1.86 with standard deviations of 0.8629 and 1.1726 respectively. Minimum and median are the same. Maximums vary significantly from 4 for the control group to 7 for the treatment group. Consequently, we observe the gamified course yielded more instances of replies, views, and total student activity. There is little to no difference regarding student posts and likes between the non-gamified course and the gamified course.

Table 2. Statistical Measures of Central Tendency and Dispersion

\begin{tabular}{|l|c|c|c|c|c|c|c|}
\hline \multicolumn{1}{|c|}{ Variable } & Group & $\begin{array}{c}\text { Total } \\
\text { Count }\end{array}$ & Mean & StDev & Minimum & Median & Maximum \\
\hline Student Posts & 1 & 248 & 1.0806 & 0.3268 & 0 & 1 & 3 \\
\hline & 2 & 236 & 1.0508 & 0.2559 & 0 & 1 & 3 \\
\hline Student Replies & 1 & 248 & 1.5161 & 0.8629 & 0 & 2 & 4 \\
\hline & 2 & 236 & 1.8559 & 1.1726 & 0 & 2 & 7 \\
\hline Likes Toward Student & 1 & 248 & 0.0645 & 0.3179 & 0 & 0 & 3 \\
\hline & 2 & 236 & 0.0424 & 0.2219 & 0 & 0 & 2 \\
\hline Views Toward Student & 1 & 248 & 27.51 & 26.59 & 0 & 18 & 140 \\
\hline & 2 & 236 & 30.81 & 20.46 & 0 & 28 & 119 \\
\hline Total Student Activity & 1 & 248 & 31.69 & 27.61 & 1 & 22 & 146 \\
\hline & 2 & 236 & 35.62 & 21.45 & 1 & 33 & 124 \\
\hline
\end{tabular}

Next, we performed 2-sample t tests in order to further analyze and compare the means of the two groups specific to each of the five dependent variables, quantifying engagement as single independent constructs. 2-sample t tests permit the comparison of two means to validate whether there is significant statistical evidence that two means are equivalent (Hair et al. 1995). The results of the 2-sample t tests are presented in Table 3. The means for the five variables for each group are shown along with the resulting p-values and confidence intervals for the significance levels investigated. We observe no significant statistical evidence that the means are different for student posts, likes, and views for either significance level $(0.05,0.10)$. Regarding student replies, the results reveal significant statistical evidence that the means are different for both significance levels. Regarding, total student activity, we note significant statistical evidence that the means are different when applying a 0.10 significance level; however, not when applying a significance level of 0.05 . 
Issues in Information Systems

Volume 21, Issue 3, pp. 20-30, 2020

Table 3. 2-Sample t Test Results

\begin{tabular}{|l|r|r|c|c|c|}
\hline & \multicolumn{2}{|c|}{ Group Mean } & & $\mathbf{0 . 0 5}$ a & $\mathbf{0 . 1 0}$ a \\
\hline \multicolumn{1}{|c|}{ Variable } & \multicolumn{1}{c|}{$\mathbf{1}$} & \multicolumn{1}{c|}{$\mathbf{2}$} & P-Value & $\mathbf{9 5 \%}$ CI & $\mathbf{9 0 \% ~ C I ~}$ \\
\hline Student Posts & 1.0806 & 1.0508 & 0.263 & $(-0.022500,0.082095)$ & $(-0.014065,0.073660)$ \\
\hline Student Replies & 1.5161 & 1.8559 & 0.001 & $(-0.52448,-0.15512)$ & $(-0.49469,-0.18492)$ \\
\hline Likes Toward Student & 0.064516 & 0.042373 & 0.373 & $(-0.026648,0.070935)$ & $(-0.018778,0.063064)$ \\
\hline Views Toward Student & 27.508 & 30.814 & 0.125 & $(-7.5320,0.92099)$ & $(-6.8503,0.23930)$ \\
\hline Total Student Activity & 31.685 & 35.619 & 0.080 & $(-8.3376,0.47128)$ & $(-7.6272,-0.23911)$ \\
\hline
\end{tabular}

Following the analysis of each of the five separate dependent variables, specifically, the effects of the group treatment specific to student posts, student replies, likes toward student, views toward student, and total student activity, we sought to assess the statistical significance of the difference between groups based on the vector representing the collective means of the first four dependent variables, student posts, student replies, likes toward student, and views toward student. Total student activity was not included in the evaluation as it represented an aggregate measure of the other four variables. The assessment was performed using Hotelling's T2, which is a specialized form of the MANOVA technique and an extension of the univariate t test (Hair et al. 1995). Hotelling's T2 is appropriate for cases where there are multiple dependent variables and one independent variable consisting of two categories -in our case, non-gamified courses vs. gamified courses. Results included a test statistic of 0.03177 , F statistic of 3.804 with 4 degrees of freedom, effect size (Partial $\eta^{2}$ ) of .031, and a p-value of 0.005. Consequently, from a collective vantage point, we reject the null hypothesis that the vector means are the same and affirm there is an overall difference regarding the effect of the two groups on the four dependent variables. We conclude an overall positive influence on the gamification of discussion boards.

RQ2: To what extent is the gamification of an asynchronous online discussion board positively related to increased cognitive performance?

Final course grades and discussion grades in both the gamified and non-gamified discussions were retrieved from the Learning Management System used in the university. Analysis consisted of statistical discovery of mean differences between the control group (non-gamified course) and the treatment group (gamified course). The same grading rubric for discussions was used by the instructor in both courses. Criteria in the discussion board rubric included quality of the original post, quality of the replies, speaker narration, and the inclusion of scholarly references.

Two forms of analysis were performed. First, the overall average final grade in both courses was examined via the 2sample $t$ test. In terms of the overall grade, students in the gamified course $(n=25)$ received an average grade of $92.8 \%$ with a standard deviation of 16.5 . The students in the non-gamified course $(n=27)$ received an average grade of $88.2 \%$ with a standard deviation of 21.52. Based on this data, we observed no significant statistical evidence $(\mathrm{P}$-value $=$ 0.3937 ) for the difference in the means for the overall grade at the .05 significance level. Secondly, the average grade for discussions only was analyzed using a 2-sample t test. The students in the gamified course $(\mathrm{n}=25)$ received an average of 57.2167 points out of a possible 60 points with a standard deviation of 1.1356 . The students in the nongamified course $(n=27)$ received an average of 54.7617 points out of a possible 60 points with a standard deviation of 1.3605. Based on this data, we observed that the means for the discussion grades in both courses are statistically different at the $95 \%$ confidence level with a two-tailed $p$ value $=0.0068$.

\section{DISCUSSION}

This study, first, demonstrated a method for the gamification of online discussions and, second, explored the effects of the proposed gamification method on student engagement in an online course. Two sources of data were combined to identify the effects of the leaderboard on behavioral and cognitive engagement. Emotional engagement was not a focus in the present study. Behavioral engagement was measured through five dependent variables measuring active 
participation with the discussion board. Cognitive engagement was measured through grades in the logs from the learning management system.

\section{RQ1-Behavioral Engagement / Active Participation}

The results partially support our expectation that a gamified discussion board will generate more total posts and replies than a non-gamified course. While there is no significant statistical evidence to support an increase in student posts, the results do favor an increase in student replies as a result of the gamified discussion board for both 0.05 and 0.10 significance levels. When considering total student activity, which includes posts, replies, likes, and views, there is statistical evidence to support an increase of engagement at the 0.10 significance level; however, when contemplating overall student engagement represented by the collective means of all five dependent variables, there is significant statistical evidence to support an overall increase of engagement at the .01 significance level. This finding is consistent with research showing leaderboards are an effective form of gamification via social comparison through competition amongst peers (Garcia et al 2013; Ding, 2019). A possible explanation for the mixed results using leaderboards is the notion that there is not "one" type of competitive process. Competition can take different forms and patterns can vary based on various factors (Fülöp, 2009). Proper design of gamification elements should, therefore, use established methodologies such as design science (Hevner, 2004) to eliminate some of the negative outcomes identified in previous studies (Hanus \& Fox, 2015; Ryan \& Deci, 2000) and encourage constructive competition (Fülöp, 2009).

The failure of the gamified course to produce more posts is likely the result of the course expectation that a student post once on a particular topic and then reply multiple times to multiple classmates. The increase in replies is reasonable considering that posting more than once regarding a particular topic might seem redundant and counterproductive. While the gamified course demonstrated an overall increase in total replies, it remains unclear if students who did not reach the top $20 \%$ of total posts/replies felt the task was too difficult. This finding supports the notion in both self-determination theory (Ryan \& Deci, 2000) and Flow theory (Csikszentmihalyi, 1998) which both state that the task should be optimally challenging for enhancing motivation. Therefore, when designing leaderboards care should be taken in consideration of the challenge level.

\section{RQ2-Cognitive Performance}

The results support our original hypothesis that a gamified discussion board will result in increased cognitive performance in discussions as evidenced by the average grade of all discussions. We did not, however, demonstrate a statistically significant difference in the overall average grade of the gamified course. The reason for this discrepancy is attributed to the fact that the overall grade reflects student performance on assignments unrelated to the discussions. The significant difference in the average grade for discussions between the gamified and non-gamified course is consistent with previous research showing that game elements can positively impact not only behavioral engagement but cognitive engagement (Ding, 2019; Huang et al. 2018). and, ultimately, learning (Kapp, 2012). A key implication of this finding is that gamification elements such as a leaderboard are just one of many tools available in designing online discussions that can induce a flow state in users (Csikszentmihalyi,1998). Elaborating concepts, debating, and/or negotiating meaning (Zhu, 2006) are all factors which have been positively correlated with improved cognitive engagement in online discussions.

\section{LIMITATIONS AND FUTURE RESEARCH}

The present study has limitations which offer significant starting points for future research. First, emotional engagement was not included as a focus for the present study. Future research should include evaluation of emotional engagement using established instruments such as the IMMS (Huang et al. 2006) or intrinsic motivation inventory (Ryan et al., 1991). The evidence of increased behavioral engagement in the form of more replies in the gamified course is assumed to be caused by increased motivation. Future research should collect self-reported data of the students to better ascertain the specific reasons for increased behavioral engagement. Second, results may not be generalizable due to the size and type of sample. The present study used a relatively small sample size of students who were business majors that could potentially be more competitive than students in other disciplines, and therefore, respond differently to a leaderboard activity. Future research should seek to employ a larger and more diverse sample size of students. 


\section{Issues in Information Systems}

Volume 21, Issue 3, pp. 20-30, 2020

\section{CONCLUSION}

To date, there is very little research on the gamification of online discussion boards and none that involve adding gamification elements to video discussion boards. Accordingly, our work makes several important contributions to the information systems literature: First, we use design science (Hevner, 2004) to provide a method for adding a leaderboard to an online discussion board and demonstrate its significance over text-based discussion boards. Second, we fulfill a significant need in gamification research for more studies which use a control group. Finally, we provide a valuable framework to address low student engagement in online discussions. From a practical perspective, our study shows that the implementation of a leaderboard as a game element for traditional online discussion boards results in increased collaboration and engagement with the discussion.

\section{REFERENCES}

Barata, G., Gama, S., Fonseca, M. J., \& Gonçalves, D. (2013). Improving student creativity with gamification and virtual worlds. Proceedings of the First International Conference on Gameful Design, Research, and Applications, 95-98. https://doi.org/10.1145/2583008.2583023

Caponetto, I., Earp, J., \& Ott, M. (2014). Gamification and education: A literature review. European Conference on Games Based Learning, 1, 50.

Cheung, W. S., \& Hew, K. F. (2005). How can we facilitate students' in-depth thinking and interaction in an asynchronous online discussion environment? A case study. 2005 Annual Proceedings-Orlando: Volume, 113.

Clark, C., Strudler, N., \& Grove, K. (2015). Comparing Asynchronous and Synchronous Video vs. Text Based Discussions in an Online Teacher Education Course. Online Learning, 19(3), 48-69.

Cowley, B., Charles, D., Black, M., \& Hickey, R. (2008). Toward an understanding of flow in video games. Computers in Entertainment, 6(2), 1. https://doi.org/10.1145/1371216.1371223

Cronk, M. (2012). Using Gamification to Increase Student Engagement and Participation in Class Discussion. 311315. https://www.learntechlib.org/primary/p/40762/

Csikszentmihalyi, M. (1998). Finding Flow: The Psychology of Engagement With Everyday Life (p. 144).

da Rocha Seixas, L., Gomes, A. S., \& de Melo Filho, I. J. (2016). Effectiveness of gamification in the engagement of students. Computers in Human Behavior, 58, 48-63. https://doi.org/10.1016/j.chb.2015.11.021

Davis, F. D. (1989). Perceived Usefulness, Perceived Ease of Use, and User Acceptance of Information Technology. MIS Quarterly, 13(3), 319-340. JSTOR. https://doi.org/10.2307/249008

Deci, E. L., Eghrari, H., Patrick, B. C., \& Leone, D. R. (1994). Facilitating Internalization: The Self-Determination Theory Perspective. Journal of Personality, 62(1), 119-142. https://doi.org/10.1111/j.14676494.1994.tb00797.x

Deci, E. L., \& Ryan, R. M. (2008). Self-determination theory: A macrotheory of human motivation, development, and health. Canadian Psychology/Psychologie Canadienne, 49(3), 182-185. https://doi.org/10.1037/a0012801

Delaney, D., Kummer, T.-F., \& Singh, K. (2019). Evaluating the impact of online discussion boards on student engagement with group work. British Journal of Educational Technology, 50(2), 902-920. https://doi.org/10.1111/bjet.12614

Deterding, S., Dixon, D., Khaled, R., \& Nacke, L. (2011). From game design elements to gamefulness: Defining "gamification." Proceedings of the 15th International Academic MindTrek Conference: Envisioning Future Media Environments, 9-15. https://doi.org/10.1145/2181037.2181040 
Dicheva, D., Dichev, C., Agre, G., \& Angelova, G. (2015). Gamification in Education: A Systematic Mapping Study. Journal of Educational Technology \& Society, 18(3), 75-88. JSTOR.

Ding, L. (2019). Applying gamifications to asynchronous online discussions: A mixed methods study. Computers in Human Behavior, 91, 1-11. https://doi.org/10.1016/j.chb.2018.09.022

Ding, L., Er, E., \& Orey, M. (2018). An exploratory study of student engagement in gamified online discussions. Computers \& Education, 120, 213-226. https://doi.org/10.1016/j.compedu.2018.02.007

Ding, L., Kim, C., \& Orey, M. (2017). Studies of student engagement in gamified online discussions. Computers \& Education, 115, 126-142. https://doi.org/10.1016/j.compedu.2017.06.016

Finn, J. D., \& Zimmer, K. S. (2012). Student Engagement: What Is It? Why Does It Matter? In S. L. Christenson, A. L. Reschly, \& C. Wylie (Eds.), Handbook of Research on Student Engagement (pp. 97-131). Springer US. https://doi.org/10.1007/978-1-4614-2018-7_5

Fredricks, J. A., Blumenfeld, P. C., \& Paris, A. H. (2004). School Engagement: Potential of the Concept, State of the Evidence. Review of Educational Research, 74(1), 59-109. https://doi.org/10.3102/00346543074001059

Fülöp, M. (2009). Happy and Unhappy Competitors: What Makes the Difference? Psihologijske Teme, 18(2), 345367.

Gao, F., Wang, C., \& Sun, Y. (2009). New Model of Productive Online Discussion and Its Implications for Research and Instruction. Journal of Educational Technology Development and Exchange, 2(1), 65-78.

Garcia, S. M., Tor, A., \& Schiff, T. M. (2013). The Psychology of Competition: A Social Comparison Perspective. Perspectives on Psychological Science, 8(6), 634-650. https://doi.org/10.1177/1745691613504114

Garrison, D. R., \& Cleveland-Innes, M. (2005). Facilitating Cognitive Presence in Online Learning: Interaction Is Not Enough. American Journal of Distance Education, 19(3), 133-148. https://doi.org/10.1207/s15389286ajde1903_2

Hair, J. F., Anderson, R. E., Tatham, R. L., \& Black, W. C. (1984a). Multivariate data analysis with readings, 1995. Tulsa, OK: Petroleum Publishing.

Hamari, J., Koivisto, J., \& Sarsa, H. (2014). Does Gamification Work? - A Literature Review of Empirical Studies on Gamification. 2014 47th Hawaii International Conference on System Sciences, 3025-3034. https://doi.org/10.1109/HICSS.2014.377

Hanus, M. D., \& Fox, J. (2015). Assessing the effects of gamification in the classroom: A longitudinal study on intrinsic motivation, social comparison, satisfaction, effort, and academic performance. Computers \& Education, 80, 152-161. https://doi.org/10.1016/j.compedu.2014.08.019

Hara, N., Bonk, C. J., \& Angeli, C. (2000). Content analysis of online discussion in an applied educational psychology course. Instructional Science, 28(2), 115-152. https://doi.org/10.1023/A:1003764722829

Hevner, A., \& Chatterjee, S. (2010). Design Research in Information Systems: Theory and Practice. Springer Science \& Business Media.

Hevner, A., R, A., March, S., T, S., Park, Park, J., Ram, \& Sudha. (2004). Design Science in Information Systems Research. Management Information Systems Quarterly, 28, 75.

Hewitt, J. (2005). Toward an Understanding of How Threads Die in Asynchronous Computer Conferences. Journal of the Learning Sciences, 14(4), 567-589. https://doi.org/10.1207/s15327809jls1404_4 
Huang, W., Huang, W., Diefes-Dux, H., \& Imbrie, P. K. (2006). A preliminary validation of Attention, Relevance, Confidence and Satisfaction model-based Instructional Material Motivational Survey in a computer-based tutorial setting. British Journal of Educational Technology, 37(2), 243-259. https://doi.org/10.1111/j.1467$\underline{8535.2005 .00582 . \mathrm{x}}$

Kapp, K. (2012). The gamification of learning and instruction: Game-based methods and strategies for training and education. San Francisco, CA: Pfeiffer.

Leong, B., \& Luo, Y. (2011). Application of game mechanics to improve student engagement. International Conference on Teaching and Learning in Higher Education.

Lepper, M. R. (1988). Motivational Considerations in the Study of Instruction. Cognition and Instruction, 5(4), 289309. https://doi.org/10.1207/s1532690xci0504_3

Lo, C. K., \& Hew, K. F. (2018). A comparison of flipped learning with gamification, traditional learning, and online independent study: The effects on students' mathematics achievement and cognitive engagement. Interactive Learning Environments, 1-18. https://doi.org/10.1080/10494820.2018.1541910

Locke, E. A., \& Latham, G. P. (2006). New Directions in Goal-Setting Theory. Current Directions in Psychological Science, 15(5), 265-268. https://doi.org/10.1111/j.1467-8721.2006.00449.x

Nakamura, J., \& Csikszentmihalyi, M. (2014). The Concept of Flow. In M. Csikszentmihalyi (Ed.), Flow and the Foundations of Positive Psychology: The Collected Works of Mihaly Csikszentmihalyi (pp. 239-263). Springer Netherlands. https://doi.org/10.1007/978-94-017-9088-8_16

Ng, C. S. L., Cheung, W. S., \& Hew, K. F. (2009). Sustaining Asynchronous Online Discussions: Contributing Factors and Peer Facilitation Techniques: Journal of Educational Computing Research. https://doi.org/10.2190/EC.41.4.e

Ryan, R. M., Koestner, R., \& Deci, E. L. (1991). Ego-involved persistence: When free-choice behavior is not intrinsically motivated. Motivation and Emotion, 15(3), 185-205. https://doi.org/10.1007/BF00995170

Silva, L. F. C. da, Barbosa, M. W., \& Gomes, R. R. (2019). Measuring Participation in Distance Education Online Discussion Forums Using Social Network Analysis. Journal of the Association for Information Science and Technology, 70(2), 140-150. https://doi.org/10.1002/asi.24080

Xu, B., Chen, N.-S., \& Chen, G. (2020). Effects of teacher role on student engagement in WeChat-Based online discussion learning. Computers \& Education, 103956. https://doi.org/10.1016/j.compedu.2020.103956

Zhu, E. (2006). Interaction and cognitive engagement: An analysis of four asynchronous online discussions. Instructional Science, 34(6), 451. https://doi.org/10.1007/s11251-006-0004-0 